\title{
Elementos de psicologia geral e do trabalho em relação biunívoca
}

\author{
Jorge Tarcísio da Rocha Falcão ${ }^{1}$
}

\section{Resumo}

O presente artigo alude à relação necessária entre qualquer domínio de aplicação específico da psicologia e uma psicologia geral. O objetivo central do presente artigo é contribuir para a proposição de uma psicologia geral capaz de fazer face à crise que presidiu seu surgimento, bem como refletir sobre a plausibilidade de uma psicologia do trabalho que se referencia por psicologia histórico-cultural. Cogeneticamente, a psicologia do trabalho aqui apresentada oferece dados empíricos e operadores teóricos específicos que avaliamos podem contribuir para o adensamento da psicologia geral à qual se filia. A relação que se estabelece entre tal psicologia do trabalho e a psicologia geral que lhe referencia é apresentada como aspecto crucial que pode vir a contribuir para a relevância da psicologia como prática profissional e domínio de conhecimento.

Palavras-chave: Psicologia Geral; Crise da Psicologia; Psicologia do Trabalho; Cogênese Psicologia Geral e do Trabalho.

\section{Elements of a general psychology and a psychology of working activity in a biunivocal relationship}

\section{Abstract}

This paper aims to discuss the necessary relationship that must preside any specific brunch of psychology and general psychology. In the present case, it is discussed the relationship between a psychology of labor activity and historical-cultural psychology. For doing so, aspects concerning the proposition of a general psychology able to rescue psychology from its constitutive crisis are reviewed. Psychology of labor activity presented here is supposed to offer both empirical data and theoretical tools that should reinforce general psychology. This mutual and cogenetic relationship between general and labor activity psychology is presented here as potentially relevant for the building up professional practice and knowledge domains.

Keywords: General Psychology; Crisis in Psychology; Psychology of Labor Activity; Cogenesis of General and Labor Psychology.

\section{Introdução}

A Psicologia enquanto ciência tem enfrentado desafios importantes em sua trajetória histórico-epistemológica. A Psicologia do Trabalho herda tais desafios gerais, aos quais incorpora desafios específicos, dentre os quais, em primeiro lugar, a própria fragilização ou inexistência de um vínculo com uma psicologia de referência - o que condena esta psicologia, assim como outras acometidas do mesmo problema grave, à condição de uma psicotécnica. Da forma como pretendemos abordar a questão aqui, a psicotécnica não consegue dar conta do trabalho na

\footnotetext{
${ }^{1}$ Universidade Federal do Rio Grande do Norte (UFRN), Natal (RN), falcao.jorge@gmail.com
} 
acepção que escolhemos como sendo crucial, e que é a acepção proposta pela Clínica da Atividade, conforme discutir-se-á mais adiante. Ora, o que chamamos aqui de abordagem psicotécnica tem sido largamente aplicada no dia a dia da gestão de recursos humanos, na abordagem de questões objetivas caras ao mundo real dos gestores envolvidos - como no domínio da seleção de trabalhadores, capacitação etc. Não obstante, apesar da aparente eficácia tópica e imediata da abordagem psicotécnica, ela não consegue dar conta do trabalho em suas dimensões cruciais e constitutivas.

Desafios que têm acometido a Psicologia desde sua origem histórica "como ciência", usualmente situada no laboratório de psicologia experimental de Wundt, em Leipzig, na segunda metade do século XIX, têm aludido à dificuldade de estabelecimento de um paradigma dominante, como ocorrido no desenvolvimento histórico da Física e da Biologia, dentre outras ciências "duras". O próprio Wundt, referenciado em manuais clássicos de história da psicologia como "pai" da psicologia científica, ao propor, no final de sua vida, uma copiosa (dez volumes) abordagem em termos de Völkerpsychologie, chama a atenção para o fato de que seria a sinergia de uma "psicologia como ciência natural" e uma psicologia tal como abordada no terreno interdisciplinar da Völkerpsychologie que permitiria pensar a abordagem da vida mental humana, a qual demandaria tanto a vertente da ciência natural quanto a vertente de uma outra psicologia (ocasionalmente chamada de "psicologia social", em aproximação ao termo original em língua alemã - Völkerpsychologie). É digno de nota, em termos históricos, a sensibilidade de Wundt no sentido de não limitar a Psicologia a uma ciência "natural", apesar de sua contribuição notável na área da psicologia experimental. Vigotski reconhecerá a importância dessa contribuição wundtiana para o esforço dele, Vigotsky, em superar a armadilha de "[...] confundir o materialismo e o naturalismo"” (VYGOTSKI, 2014, p.24).

Nos supracitados domínios da Física e da Biologia, a disputa entre paradigmas newtoniano e relativístico, na Física, e entre a ênfase em caracteres adquiridos (Lamarck) e ênfase na evolução das espécies em decorrência de seleção natural de espécimes à maior ou menor adaptabilidade ao meio circundante (Darwin), na Biologia, ensejou momentos de crise e de mudanças paradigmáticas dramáticas (KUHN, 1978). Tais crises, não obstante a faceta de

\footnotetext{
2 "[...] confondre le matérialisme avec le naturalisme".
} 
desconstrução no momento em que eclodiram, ensejaram evolução ${ }^{3}$ considerável em tais domínios de conhecimento. Tal evolução, que para alguns autores aparece como privilégio dos chamados domínios paradigmáticos do conhecimento (conforme exemplos aqui sugeridos na Biologia e na Física), não estaria ao alcance dos chamados "domínios pré-paradigmáticos", no contexto dos quais não seria possível constatar um paradigma dominante a enquadrar todo um circuito de "ciência normal" (KUHN, 1978).

Thomas Khun identifica, nos domínios de conhecimento por ele denominado de "préparadigmáticos ${ }^{4 \prime}$, a produção de embates que engendrariam mais calor do que luz, conforme a expressão popular. Tais embates ocorreriam em contexto pré-paradigmático, o qual, na ausência de um paradigma unificador que pudesse ensejar uma produção de pesquisa "normal" (KHUN, 1978) e adensadora das teorias alimentadoras do paradigma, geraria crises no sentido aludido por Vigotski (2010) em Significação histórica da crise em psicologia - crises em busca da constituição da hegemonia de um paradigma ainda por construir. Nesta obra, uma das contribuições mais lúcidas para o adensamento do diagnóstico e saídas para a crise da Psicologia, Vigotski estabelece, como ponto de partida da referida crise, a disputa entre perspectivas idealistas e naturalistas em Psicologia, e como ultrapassagem desse impasse, a busca por uma "terceira via", para a qual seriam candidatas a psicologia da Gestalt, o Personalismo e a psicologia marxista. Nenhuma das três, finalmente, cumpriria os requisitos básicos estabelecidos por Vigotski para a superação da referida crise, e construção de uma terceira via que resolvesse o dilema entre o idealismo e o naturalismo.

A discussão acerca do eventual caráter pré-paradigmático da Psicologia não deixa de ter seu interesse, mas não será o foco aqui. Passaremos igualmente ao largo de um aprofundamento da discussão acerca do quão marxista é (ou seria) a proposta de uma psicologia histórico-cultural que, para Vigotski, representaria efetivamente o tão esperado passo adiante para a superação da crise que remonta ao nascedouro da Psicologia, e perdura até os dias atuais. O objetivo central, aqui, partirá da abordagem de pontos a contemplar por parte de uma proposta teórica

\footnotetext{
3 Para alguns, tal evolução configuraria uma verdadeira quebra de paradigma, e consequentemente uma "revolução" (KHUN, 1978), enquanto para outros a ideia mesma de descontinuidade de uma perspectiva em relação àquela que Ihe sucede não encontraria respaldo em dados históricos, segundo os quais haveria sempre "antecedentes" de um paradigma aparentemente revolucionário no zeitgeist científico-acadêmico que o precede (LAKATOS, 1987).

${ }^{4}$ Os quais, a bem da lógica interna do discurso de Khun (1978), serão alternativamente denominados "pré-cientificos".
}

Periódico Horizontes - USF - Itatiba, SP - Brasil - e021029 
em psicologia geral que tenha sustentação. Tal discussão tem como foco a Psicologia, mas poderia abranger outros domínios do conhecimento, notadamente no bojo das Humanidades. Essa discussão meta-teórica inicial buscará defender a necessidade de se considerar, no polo mais concreto e operacional do fazer científico em Psicologia (como também alhures), as ferramentas, procedimentos, preceitos, rotinas e sub-rotinas que corporificam o método, e no polo mais abstrato, as filiações de caráter ontológico-epistemológico; tais polos abarcam, do lado do abstrato, o sistema teórico de filiação, e do lado concreto, as especificações em termos de metodologia. Tais pontos aqui referidos não devem ser vistos linearmente, como itens de checagem; a metáfora representacional mais adequada, aqui, seriam as matrioskas russas ${ }^{5}$, nas quais bonecas de tamanhos cada vez menores se inserem umas nas outras: as maiores abarcam as menores - a metodologia abarca o método e as ferramentas, tais como rotinas, testes e questionários, e é abarcada pelo sistema teórico, que se insere numa epistemologia, proposta de unidade de análise do domínio cientifico e ontologia do humano.

Na seção seguinte tentaremos resumir a crise histórica da psicologia em termos do enfrentamento da tarefa metateórica de proposição de uma psicologia geral. Conforme comentado acima, elementos da análise vigotskiana da referida crise, tal qual expostos em seu livro publicado em 1929, e de cuja tradução francesa faremos uso (VYGOTSKI, 2010). Feita essa breve retomada, a reflexão aqui proposta evoluirá na direção do que seria uma psicologia do trabalho tributária de uma psicologia geral que a referencie, seguindo-se a abordagem de qual poderia ser, biunivocamente, o aporte que esta psicologia do trabalho poderia retroativamente oferecer à psicologia geral de onde emergiu. Os desdobramentos do presente esforço para o desenvolvimento de uma psicologia do trabalho relevante, eticamente fundada e teoricamente consistente serão abordadas na seção final de conclusão. Concomitantemente, avaliaremos a contribuição dessa dinâmica para o desenvolvimento de uma psicologia geral que efetivamente

\footnotetext{
5 “Matrioskas (ou Matryoshkas - do russo матрёшка - transliteração para o alfabeto ocidental Matrëška), também conhecida como boneca russa, é um brinquedo tradicional da Rússia, que se tornou também um símbolo e souvenir desse país. Constitui-se de uma série de bonecas, feitas geralmente de madeira, colocadas umas dentro das outras, da menor até a maior" (https://pt.wikipedia.org/wiki/Matriosca). O uso metafórico das matrioskas para aludir a níveis subsumidos de instâncias teóricas referentes à construção de uma psicologia geral, bem como de uma psicologia do trabalho, nos foi sugerido em conferência não-publicada da Profa Katia Kostulski em Natal-RN-Brasil (UFRN-Programa de Pós-Graduação em Psicologia, 2016), conferência intitulada "Langage, activité et devéloppement", que se apoiou nessa metáfora ilustrativa para representar as instâncias desenvolvimentais da linguagem.
}

Periódico Horizontes - USF - Itatiba, SP - Brasil - e021029 
pode contribuir para a superação da crise constitutiva da psicologia contemporânea.

Cabe aqui observar, no fechamento deste preâmbulo, o risco que corremos na proposição do presente texto, que se dispõe a abordar aspectos e elementos de análise que vão da história da psicologia à psicologia teórica, passando pela psicologia do trabalho e pela abordagem metateórica, com resultado final que poderia sugerir excesso de itens de análise e consequente ligeireza exagerada de abordagem. Esforços foram feitos, contudo, para que a referida ligeireza de abordagem não fique exagerada, pois ligeireza (no sentido de um esforço limitado por um gênero textual) necessariamente haverá. Buscou-se aqui, nos limites de um artigo acadêmico, contribuir para uma agenda de pontos de ataque de diversas origens para a abordagem do que Vigotski chamou, já no título de livro publicado em 1926, a "significação histórica da crise da psicologia" (VYGOTSKI, 2010), que perdura até hoje.

\section{Elementos a retomar na análise da crise histórica da psicologia}

Para S. Koppe (2011), “[...] qualquer processo científico se inicia com uma definição teórica (explícita ou implícita) de um objeto reconhecido, através de uma seleção dentre as características dos objetos reais"6 (grifos meus). Em outras palavras, qualquer domínio do conhecimento precisa de um quadro de referência que lhe forneça princípios para os recortes do real, com desdobramentos metateóricos e metodológicos. A Física Clássica, comentada anteriormente, se baseou nas Três Leis de Newton. A Física Relativística, por sua vez, incorporou essas três leis como um caso particular, abarcado e ultrapassado pela Lei Geral da Relatividade. A Biologia se baseia, desde Darwin, na Lei Geral da Evolução das Espécies.

Em que princípio geral se baseia a Psicologia? Não há, justamente, um tal princípio geral, mas uma disputa histórica, o que configura a crise aludida e dissecada por Vygotski (2010). Tal disputa, segundo o referido autor, abarcou duas tentativas: a ênfase numa psicologia "idealista", centrada sobre a "consciência" e sobre "processos mentais" - donde o epíteto de "psicologia espiritualista" que receberá eventualmente; noutro extremo, abarcou a psicologia "naturalista", que buscou programaticamente descrever o psiquismo com os mesmos operadores teóricos e

\footnotetext{
6 "Any scientific process begins with a theoretical definition (explicit or implicit) of a recognized object by selecting among the real objects' characteristics" (KOPPE, 2011, p.3).
}

Periódico Horizontes - USF - Itatiba, SP - Brasil - e021029 
metodológicos mais gerais das ciências "duras" - donde o epíteto de "psicologia naturalcientifica" (VYGOTSKI, 2010, p.249). Nenhuma dessas duas correntes em disputa ensejou estabelecer, para a psicologia, uma lei ou princípio geral capaz de oferecer saída para a crise. A psicologia marxista, para muitos (notadamente no Brasil) seria forte candidata a suprir a psicologia com esse princípio geral, mas conforme observa o próprio Vigotski, o estabelecimento de relação entre a Psicologia e o Marxismo vai ALÉM da proposição de uma Psicologia em "acordo" com o Marxismo. A Psicologia demanda uma meta-teoria específica que permita estabelecer vínculos adequados entre Teoria e Método. Essa meta-teoria não deve ser "herdada" da filosofia, ou de outras ciências. N. Veresov observa que para os domínios da economia, ciência política, história e sociologia, uma matriz teórica e metateórica importante foi estabelecida por Karl Marx com o seu Das Capital (VERESOV, 2005). Ora, estender esta obra de referência à psicologia seria, para Veresov, abusivo: "a psicologia precisaria de seu próprio Das Capital”, diz ele, e cita Vigotski em apoio a essa proposição:

Para criar essas teorias de referência, capazes de fornecer metodologias em ciências gerais, é necessário atingir a essência de uma dada circunscrição de fenômenos, as leis de suas mudanças, suas características qualitativas e quantitativas, sua causalidade; é necessário criar categorias e conceitos relevantes para estes fenômenos - em outras palavras, criar o seu próprio Das Capital (VYGOTSKY, 1982, pg. 420, apud VERESOV, 2005, p.37) ${ }^{7}$.

E Vigotski conclui: “Consequentemente, categorias, conceitos e leis neste Das Capital da psicologia devem ser psicológicos, e não filosóficos"8 (VYGOTSKY, 1982 apud VERESOV, 2005, p.37).

Historicamente, a questão da busca da Psicologia pelo "seu" O Capital se insere, portanto, num debate mais amplo, que seria a proposição de uma psicologia de base marxista como sendo aquela que resolveria a "crise histórica" da psicologia, no contexto dos anos vinte do século passado (VIGOTSKI, 2010). Este autor destaca os esforços então em voga na recém-surgida URSS

\footnotetext{
7 "In order to create such enabling theories - methodologies in general sciences - it is necessary to discover the essence of the given area of phenomena, the laws of their changes, their qualitative and quantitative characteristics, their causality; to create the categories and concepts relevant to them - in other words, to create one's own Capital." (VYGOTSKY, 1982, p.420).

8 "Consequently, the categories, concepts and laws in this Capital must be psychological but not philosophical one." (VYGOTSKY, 1982, p.420).
} 
para superar tal crise: a revolução de 1917 teria estabelecido as bases políticas e ideológicas a partir das quais a academia soviética buscou orientar todo o esforço de produção acadêmicointelectual em bases marxistas; no contexto desse esforço, a saída para a crise da psicologia (mas não só dela) seria a evolução rumo a uma "Psicologia materialista", e tal psicologia materialista, por sua vez, encontraria sua devida especificação numa psicologia marxista (VERESOV, 2005; TOASSA, 2016). Vygotski analisa a "candidatura" de uma psicologia marxista como saída para a crise em análise, juntamente com as alternativas oferecidas, à época, pela psicologia da Gestalt e pelo Personalismo, e descarta as três. No que diz respeito à psicologia marxista, Vygotski questiona até o fato de haver, efetivamente, uma tal psicologia. Escreve ele:

Não há ainda, em última análise, uma psicologia Marxista. [A proposição de uma tal psicologia] deve ser encarada como uma tarefa histórica, e não como algo dado. Não obstante, no contexto atual, é difícil evitar a impressão de haver considerável falta de seriedade científica e responsabilidade nessa denominação [de psicologia Marxista] (VYGOTSKY, 1982 p.433). ${ }^{9}$

A esse parágrafo bastante incisivo pode ser acrescido outro trecho, oriundo de outra obra mas voltado para a mesma discussão:

O último sistema que tenta constituir uma terceira via é o sistema da psicologia marxista, que está em vias de se formar diante de nossos olhos. A análise desse sistema é difícil, porque ele ainda não dispõe de sua própria metodologia, e se esforça em encontrá-la pronta nas observações fortuitas dos fundadores do marxismo, sem mesmo se dar conta que achar uma fórmula pronta [toute faite, no texto original da tradução francesa] do psiquismo nas obras dos outros resulta na proposição da 'ciência antes da própria ciência' ['la science avant la sicence elle-même'] (VYGOTSKI, 2010, p.250, itálicos-negritos adicionados). ${ }^{10}$

Quando Vygotski alude à impossibilidade da Teoria Marxista (através d'O Capital)

\footnotetext{
${ }^{9} \mathrm{Na}$ tradução em língua inglesa, a partir do russo: “"Ultimately, there is no Marxist psychology as yet. This must be seen as a historical task, not as something given. But in the present state of affairs it is difficult to avoid the impression that there is a considerable lack of scientific seriousness and responsibility surrounding this appellation." ${ }^{10} \mathrm{Na}$ tradução em língua francesa, a partir do russo: "Le dernier système qui tente d'emprunter une troisième voie est le système de la psychologie marxiste, qui est en train de se former sous nos yeux. Son analyse est difficile, parce qu'il ne dispose pas encore de sa propre méthodologie et qu'il s'efforce de la trouver toute faite dans les propos psychologiques fortuits des fondateurs du marxisme, sans même se rendre compte que trouver une formule toute faite du psychisme dans les œuvres des autres revient à exiger 'la science avant la science elle-même'.
}

Periódico Horizontes - USF - Itatiba, SP - Brasil - e021029 
referendar, subsidiar, fornecer o terreno teórico, epistemológico e metodológico para uma Psicologia geral, ele próprio, na sequência, propõe que sim, seria necessária uma teoria de referência, mas não uma "psicologia marxista baseada n'O Capital" - seria o caso da Psicologia buscar o seu próprio O Capital... Esse é um ponto polêmico, notadamente diante de uma perspectiva que insista em identificar na contribuição vigotskiana uma "psicologia marxista". Para os prefaciadores da Histoire du développement des fonctions psychiques supérieures, de Lev Vygotski (VYGOTSKI, 2014, p.07-76), Michel Brossard e Lucien Sève, ESTE livro teria sido inicialmente concebido com a finalidade de suprir esta lacuna crucial. Para muitos leitores da obra vygotskiana, este objetivo de fôlego não teria sido suficientemente atingido com a referida obra, tendo em vista circunstâncias da época de sua feitura, como o clima político vigente e o adoecimento e morte prematura do autor.

Cabe finalmente observar que a crítica a uma proposta de assimilação da psicologia histórico-cultural à perspectiva marxista é aqui assumida, mas não como uma postura original nossa, e sim como alinhamento em relação à perspectiva baseada na própria análise vigotskiana em Vygotski (2010).

A lei geral mais fundamental de uma psicologia capaz de superar a crise histórica da psicologia não viria da psicologia da Gestalt, nem de uma psicologia personalista (como a proposta por Stern apud Vygotski, 2010), e nem de uma psicologia marxista, mas da psicologia histórico-cultural, nos termos da Lei Geral do Desenvolvimento Cultural:

[...] qualquer função [mental] no contexto do desenvolvimento cultural da criança aparece duas vezes, ou seja, em dois planos. Primeiramente, esta função aparece no plano social, e em seguida, no plano psicológico. Primeiramente entre pessoas, como uma categoria interpsicológica, e então como função internalizada pela criança, como uma categoria intrapsicológica. Isto é igualmente verdadeiro no que diz respeito à atenção voluntária, memória lógica, formação de conceitos e o desenvolvimento da volição (VYGOTSKY, 1982, p.145) ${ }^{11}$

Essa lei fundamental estrutura a unidade de análise de uma psicologia geral voltada para

11 “[...] any function in the child's cultural development appears on stage twice, that is, on two planes. It firstly appears on the social plane and then on a psychological plane. Firstly among people as an inter-psychological category and then within the child as an intra-psychological category. This is equally true with regard to voluntary attention, logical memory, the formation of concepts and the development of volition" (VYGOTSKY, 1983, p.145).

Periódico Horizontes - USF - Itatiba, SP - Brasil - e021029 
o desenvolvimento das funções mentais superiores (VYGOTSKI, 2014), o que terá rebatimento crucial para um contexto em que tais funções serão centrais - a atividade de trabalho, no âmbito de uma psicologia do trabalho que se insere no quadro mais geral da psicologia histórico-cultural.

\section{Da psicologia geral à psicologia do trabalho}

Yves Clot (2010b) chamou a atenção para o fato de que "todas as psicologias específicas devem ter uma psicologia geral de referência". Por outro lado, o mesmo Yves Clot observou, ressaltando sua concordância com Vigotski, que "[...] o desenvolvimento não é somente objeto de uma "psicologia geral". É o método prático a desenvolver em cada especialidade"12 (CLOT, 2012, p.13). Isso se deve ao fato, ainda segundo Clot, de haver

[...] alguma coisa 'geral' que transita e circula, por exemplo, entre a psicologia da criança e a psicologia do trabalho: o desenvolvimento possível ou impedido do sujeito humano, esse sujeito que pode transformar a atividade coletiva em recurso para sua atividade própria, ou fracassar nessa tentativa (CLOT, 2012, p.14)..$^{13}$

A Lei Geral do Desenvolvimento Cultural estabelece a cogênese das funções mentais superiores, tendo em vista que toda e qualquer atividade humana é mediada por sua inserção histórico-cultural; desse princípio vai resultar uma das bases fundamentais de uma psicologia do trabalho assentada sobre os princípios de uma psicologia do trabalho histórico cultural: trata-se da premissa segundo a qual a atividade de trabalho prescrita não é passível de plena realização quando passa à condição de atividade de trabalho real (CLOT, 1999, 2008; DA ROCHA FALCÃO, 2019b). O trabalho prescrito, enquanto formulação que emana de um coletivo ou instância organizacional, jamais poderá ser realizado em sua plenitude, pois entre o que se prescreve e o que se obtém na atividade real dos trabalhadores haverá sempre um processo de mediação em que colidem os que prescrevem e os que recebem a prescrição e a executam; os que canalizam

\footnotetext{
12 “[...] le développement n'est pas seulement l'objet d'une "psychologie générale”. C'est la méthode pratique qu'il faut éprouver dans chaque spécialité."

13 "Il y a quelque chose de "général" qui transite et circule, par exemple, entre la psychologie de l'enfant et la psychologie du travail: le développement possible ou empêché du sujet humain, ce sujet qui peut transformer l'activité collective en ressource pour son activité propre ou encore échouer à le faire" (CLOT, 2012, p.14).
} 
o saber-fazer acumulado no acervo de um gênero profissional ${ }^{14}$, e os que adicionam ao prescrito por esse gênero elementos de um estilo pessoal. Da Rocha Falcão (2019b) observa, nesse sentido, que se toda função mental superior foi inicialmente externa ao indivíduo antes de ser internalizada por ele (VYGOTSKI, 2014; VYGOTSKY, 1994), a passagem dramática do trabalho socialmente prescrito ao trabalho efetivamente realizado está na base do desenvolvimento da própria atividade de trabalho - tanto em termos individuais quanto em termos do desenvolvimento do gênero profissional que referencia este indivíduo-trabalhador (CLOT, 2006, 2008). Da Rocha Falcão (2019b) ressalta o caráter necessariamente dramático dessa passagem, tendo em vista a colisão que necessariamente advém do fato de que a prescrição social do trabalho somente se torna exequível depois de ressignificada (via linguagem contextualizada) pelo indivíduo trabalhador.

A situação dramática acima aludida, que embasa uma psicologia do trabalho de base histórico-cultural, tem desdobramentos importantes em termos de recortes conceituais e ênfases daquela psicologia do trabalho. Dois exemplos ilustram essa constatação: em primeiro lugar, a abordagem clássica das "competências" e "habilidades", e em segundo, a abordagem da questão da precariedade / precarização da atividade de trabalho. Abordemos brevemente cada uma dessas vertentes de uma psicologia do trabalho inserida no quadro de referências de uma psicologia geral apoiada na perspectiva histórico-cultural.

A centralidade da Lei Geral do Desenvolvimento Cultural torna insustentável a abordagem individualista de competências e habilidades como construtos DO / NO indivíduo (da qual resultam prescrições importantes para domínios como a seleção profissional e avaliação de desempenho - conforme discute, dentre outros, Zarifian $(2003,2009))$. O que determinado indivíduo é capaz de fazer, em contexto mais geral de resolução de problemas (sejam eles problemas escolares ou desafios da vida extra-escolar - conforme Da Rocha Falcão (2009)), abarca não somente um acervo de competências disponíveis e ao alcance do sujeito, mas

\footnotetext{
${ }^{14}$ Da Rocha Falcão (2019b) comenta que o operador teórico gênero profissional é apropriado pela psicologia do trabalho fundada na Clínica da Atividade (CLOT, 1999; 2008) a partir do conceito de gênero do discurso em Bakhtin (CLOT, 2008, p.149). Em seu texto, Da Rocha Falcão (2019b) transcreve a definição de Clot para gênero profissional em termos de "[...] um respondente [répondant] profissional que, atravessando a atividade profissional de cada trabalhador [referenciado por este gênero], põe justamente este trabalhador na intersecção do passado e do presente. Dito de outra forma, o gênero profissional é o respondente genérico do ofício [répondant générique du métier] (CLOT, 2008, p.149 - tradução nossa).
} 
também competências que se realizam com algum suporte externo de mediação - seja ele oriundo de um parceiro, de uma ferramenta cultural (BRUNER, 1997) ou de ambos. Esse princípio, estabelecido no corpus da psicologia histórico-cultural, inicialmente traduzido como "zona de desenvolvimento proximal", e mais recentemente como "zona de desenvolvimento iminente ${ }^{15 "}$, é definido por Vigotski (2021, p.190) nos seguintes termos:

A zona de desenvolvimento iminente indica as funções que ainda não amadureceram e encontram-se em processo de amadurecimento, funções que amadurecerão amanhã, que ainda se encontram em estado embrionário; são funções que não podem ser denominadas de frutos, mas de brotos, flores, ou seja, o que está começando a amadurecer.

Tal perspectiva interacional e cogenética do desenvolvimento ultrapassa a perspectiva mais tradicional das competências, habilidades e conhecimentos como dotações individuais, "capital" simbólico de que cada um disporia "dentro" de sua própria cabeça. No contexto das competências e habilidades que são esperadas de determinado indivíduo em sua atividade de trabalho - como o piloto da aviação civil que precisa lidar com situação menos corriqueira num pouso ou aterrisagem - é crucial considerar não somente o que este piloto possa fazer sozinho, mas o que possa fazer em interação com um colega co-piloto; nesse sentido, haveria a competência para abordar um problema, e a competência de avaliar a necessidade de ajuda e a capacidade de buscar e obter essa ajuda: ambas extremamente relevantes no domínio do trabalho real. Este princípio traz consequências importantes para a avaliação de desempenho, bem como para o estabelecimento dos tradicionais perfis de "competências críticas" para determinado ofício profissional (PASTRÉ; MAYEN; VERGNAUD, 2006).

Em segundo lugar, a perspectiva histórico-cultural em psicologia geral terá repercussão importante, em psicologia do trabalho, para a abordagem dos riscos psicossociais e da precariedade/precarização no contexto do trabalho, com especial ênfase em aspectos externos (e como tais passíveis de "higiene"), como os assédios, a ecologia dos postos de trabalho, a precificação do trabalho via salário, horários/turnos de trabalho, regulamentação/ proteção

\footnotetext{
${ }^{15}$ Essa foi a tradução do russo para o português brasileiro proposta por Zoya Prestes e Elizabeth Tunes, a partir do texto "A dinâmica do desenvolvimento mental do escolar e a instrução", um dos capítulos presentes na compilação de escritos de Vigotski, "Psicologia, educação e desenvolvimento" (VIGOTSKI, 2021, p.175-207).
} 
social pelo Estado, e assim por diante. A chamada perspectiva "higienista" acerca da precariedade/precarização da atividade de trabalho não se sustenta no âmbito de uma psicologia do trabalho de base histórico-cultural (CLOT, 2008, 2010; DA ROCHA FALCÃO, SILVA MESSIAS; MASCARENHAS DE ANDRADE, 2020a; 2020b). A alusão a "higiene" e "abordagem "higienista" diz respeito a uma abordagem de fatores sobretudo externos, e passíveis portanto de higiene (estrito senso), como é. caso de agravos à saúde e ao bem-estar como fontes de infecção/contágio, radiações ionizantes, condições de temperatura e iluminação, dentre outras fontes claramente externas.

A abordagem da Clínica da Atividade, em psicologia do trabalho, contrapõe à perspectiva higienista acerca da gênese dos riscos psicossociais, aqui incluídos o adoecimento e morte (eventualmente devida ao suicídio) devido ao trabalho, a ênfase na margem de ação do indivíduo-trabalhador no que diz respeito ao trabalho que realiza, em face do trabalho que lhe é prescrito. Tal margem de ação constituirá um dos operadores teóricos centrais da proposta da Clínica da Atividade, o poder de agir de cada trabalhador (CLOT, 2006, 2008). Tal construto teórico se assenta sobre o dinamismo estabelecido pelas colisões dramáticas acima aludidas (DA ROCHA FALCÃO, 2019b), colisões que ocorrerão entre cada trabalhador-individual e seu coletivo de trabalho ${ }^{16}$, e que dizem respeito ao reconhecimento por este trabalhador, das regras de trabalho coletivo como dos demais, mas também dele - observe-se aqui, mais uma vez, a centralidade fundante da Lei Geral do Desenvolvimento Cultural. Tal dinâmica, diga-se de passagem, nem sempre é bem-sucedida: o indivíduo pode vir a se deixar oprimir e anular pelo coletivo, do qual pode vir a se tornar um mero "boneco de ventríloquo" - conforme metáfora proposta por M. Bakhtin (BAKHTINE, 1984). Nessa metáfora, o boneco, sentado no colo do ventríloquo, "parece" ter voz própria, mas é de fato seu mestre quem fala, mesmo que pareça não falar. Desconstruindo a metáfora, muitos trabalhadores apenas tentam repetir ipsis litteris os preceitos de um manual (real ou imaginário) voltado para o desempenho de determinação

\footnotetext{
${ }^{16}$ Yves Clot chama a atenção para a importância e interesse desse operador teórico. A partir da elaboração original de D. Cru, por sua vez tributária da contribuição do Círculo Bakhtin (BAKHTINE/VOLOCHINOV, 1977), Clot observa que o coletivo de trabalho é constituído por "[...] vários trabalhadores, uma obra comum, uma linguagem comum, regras internas ao trabalho ["règles de métier", no original], respeito durável pelas regras da parte dos trabalhadores, o que impõe uma dinâmica individual que parte do conhecimento da regra à sua interiorização" (CLOt, 2008, p.147). Constituir-se como membro de um coletivo de trabalho, observa Clot, implica na realização de um "trabalho ao quadrado" ["métier au carré", no original], no sentido de um trabalho a ser realizado sobre o trabalho.
} 
função profissional, sem ainda se permitir um poder mínimo de ação estilizadora própria. No outro extremo, o indivíduo-trabalhador pode levar sua inovação estilizadora a um extremo que gera reação de estranhamento hostil da parte do gênero. Clot e Faïta (2000) observam que o gênero de atividades profissionais é funcional na medida em que fornece, ao mesmo tempo, dificuldades e recursos aos profissionais para controlar seus atos [...]. Nesse sentido, de forma semelhante ao que ocorre no domínio dos gêneros discursivos, o gênero profissional oferece uma espécie de estoque "[...] de maneiras diversificadas de pensar e de fazer o trabalho, [...] estabilizadas e admitidas entre os pares num dado meio profissional." Os trabalhadores dispõem dos recursos do gênero para poder agir, pois, "se fosse preciso criar, todas as vezes que agimos, cada uma de nossas atividades, o trabalho se tornaria impossivel. (CLOT; FAÏTA, 2000, p.11).

As considerações acima acerca da relação cogenética entre as estilizações individuais de cada trabalhador e o gênero profissional que os referencia permite evoluir na direção da seguinte constatação: estes confrontos entre variantes estilísticas e gênero de referenciamento caracterizam a vitalidade de determinado gênero. Nesse sentido, a precarização da atividade de trabalho é aqui revista e ampliada no sentido de superar a perspectiva clássica e "higiênica" de aspectos precarizantes externos (frequente, por exemplo, no chamado "trabalho sujo" conforme Bendassoli e Da Rocha Falcão (2013); Lhuilier (2005)). Tal ampliação conduz à consideração da fragilidade / inexistência de um gênero de referenciamento, que condena o trabalhador a níveis variáveis de solidão profissional, como aspecto crucial para a abordagem da precarização, e mesmo revisão do conceito de "trabalho sujo". Bendassolli e Da Rocha Falcão (2013) propõem, portanto, a passagem do conceito de "trabalho sujo" para o conceito de trabalho precário por conta do ponto aludido acima, referente ao empobrecimento dos gêneros profissionais, indutor de empobrecimento de referenciamento para o indivíduo-trabalhador, bem como por conta da constatação de certo "esgotamento conceitual" do termo "trabalho sujo" (KOPPE, 2011). Tal esgotamento tem relação com a seguinte constatação: o termo "trabalho sujo" abarca uma imensa heterogeneidade de "tipos" de sujeira e, portanto, de trabalhos sujos, como é o caso da "sujeira moral" (para o ofício das prostitutas, por exemplo); da sujeira relacionada a sentimento de "nojo/asco", no caso dos lixeiros, coveiros, necropsiadores e assemelhados; da sujeira relacionada a repulsa social, dirigida a ofícios como gestão da execução de condenados à pena capital ("carrascos"), como também no caso de médicos encarregados de 
auxiliar pacientes a morrer ("cuidados paliativos" - que contrariam, em si e por si, a representação social dominante dos médicos como sendo aqueles que confrontam e vencem a morte). Tal diversidade de acepções daria ao conceito de "trabalho sujo" uma abrangência excessiva, que contribuiria para a perda de eficácia do conceito enquanto tal (KOPPE, 2011).

Um aspecto central da psicologia histórico-cultural que referencia a psicologia do trabalho aqui apresentada, e que foi sistematizada pela Clínica da Atividade (CLOT, 2010a), diz respeito, em última análise, ao caráter dialógico e cogenético que preside a dinâmica de desenvolvimento das funções mentais superiores (VYGOTSKI, 2014). Tal caráter cogenético e dialógico exige, em primeira instância, a consideração de um indivíduo humano submetido a determinado contexto social, histórico e cultural, em conformidade com o que se estabelece já nas primeiras formulações da Lei Geral do Desenvolvimento Cultural ${ }^{17}$. Ora, a consideração de um indivíduo em contexto tem posto para a psicologia situações clássicas de embate teórico acerca do papel de fatores "externos" ("ambientais", "contextuais", "sociais" etc.) e fatores "internos" ("biológicos", "herdados", "orgânicos", "subjetivos", "idiossincráticos" etc.). Jerome Bruner, em excelente artigo no qual rendeu homenagem ao centenário de nascimento de dois gigantes da Psicologia - Jean Piaget e Lev Vigotski - chamou a atenção para uma avaliação superficial (porém bastante disseminada) de um e outro desses teóricos em termos de uma ênfase em aspectos biológicos-individuais por um deles (Piaget), e ênfase em aspectos sócioculturais extra-individuais pelo outro (Vigotski) (BRUNER, 1997). Tal crítica, ressaltou Bruner, parte de uma concepção de "individual" e "social" como se fossem polos passíveis de interação, porém circunscritos, cada um deles, em sua respectiva especificidade ontológica. Teríamos aqui, conforme ressalta Ivana Markovà, o "indivíduo" e o "outro" em "interação" (MARKOVÀ, 2000; 2006). Essa perspectiva simplificadora assimila Piaget a uma perspectiva que enfatizaria o indivíduo, em detrimento do social, e assimila Vigotski a perspectiva oposta, que enfatiza o social, em detrimento do individual. Não vamos nos deter aqui em relação à superficialidade da crítica em relação a Jean Piaget, tendo em vista o foco do presente artigo, mas registramos o quanto tal crítica se distancia de um dos pontos mais centrais da perspectiva cogenética e

\footnotetext{
${ }^{17}$ Lembrando mais uma vez: "[...] qualquer função [mental] no contexto do desenvolvimento cultural da criança aparece duas vezes, ou seja, em dois planos. Primeiramente, esta função aparece no plano social, e em seguida, no plano psicológico. [...]." (VYGOTSKY, 1983, p.145. Vygotsky, L. S. (1983). Sobranie sochinenii [The collected works]. Moscow, Pedagogica, vol. 3. In: VERESOV, 2005, p.38).
} 
dialógica que constituem o "núcleo duro" (LAKATOS, 1987) da proposta da psicologia históricocultural. Ora, cogênese e perspectiva de um self dialógico ultrapassam a mera admissão de um "outro" com o qual determinado "self" interage: o filósofo Martin Buber, um dos precursores da perspectiva dialógica e cogenética, resume numa frase o aspecto crucial aqui: "O Eu se torna Eu em virtude do Tu" (BUBER, 1974, pg. XLIX) ${ }^{18}$. Em termos de processos mentais superiores de produção de significado, algo que dizem para mim não é passível de assimilação integral de minha parte, assim como o que eu digo para terceiros não é passível de assimilação rigorosa e na íntegra da parte de que recebe minha mensagem, até porque nem eu próprio tenho controle completo acerca do sentido e significado de minha elocução, pois sentido e significado somente concluir-se-ão com o concurso do OUTRO ou de OUTROS - donde a proposição central de Buber, comentada acima. Tal abordagem dialógica e cogenética das funções mentais superiores, unidade de análise da psicologia (VYGOTSKI, 2014), guarda relação direta com o caráter semiótico da linguagem, conforme ressalta o Círculo Bakhtin (notadamente Bakhtine/Volochinov, 1977). O desdobramento dessas considerações, numa psicologia do trabalho referenciada pela psicologia histórico-cultural, nos conduz coerentemente ao princípio segundo o qual o trabalho prescrito jamais poderá ser realizado em sua integralidade (posto que jamais poderá ser recebido na íntegra para o trabalhador que recebe a prescrição), e ao segundo princípio diretamente associado ao primeiro, aquele referente à importância dos coletivos e do gênero profissional para a preservação do poder de agir do trabalhador, rumo ao ideal do trabalho bem-feito. Afinal, nenhum trabalho se realiza (se concretiza, se desenvolve na prática) sem que se negocie o que se pode fazer, o que se deseja fazer, as alternativas a esse fazer, a escolha dentre possibilidades concorrentes. $O$ trabalho que é feito é tão somente a possibilidade "vencedora" dentre as várias possibilidades que se apresentam ao sujeito e a seus colegas, no âmbito dos coletivos de trabalho. Assim como na produção escrita, o autor busca ser fiel ao gênero textual que o referencia (o "romance" ou "novela", por exemplo), ao mesmo tempo em que tenta trazer sua contribuição específica, sua estilização para esta obra textual, que finalmente deverá ser reconhecível como "romance", mas suficientemente original para não ser, meramente, só mais um romance... (BAKHTINE, 1984). No

\footnotetext{
${ }^{18}$ Buber ressalta que dessa afirmação não decorre que o Eu deve ao Tu o "seu lugar", e nem vice-versa. O Eu deve ao Tu a relação com ele: "Ele é meu Tu somente na relação, pois, fora ela, ele não existe, assim como o Eu não existe a não ser na relação" (BUBER, 1974, p.XLIX - itálico-negrito acrescentado).
} 
âmbito da atividade profissional do piloto de aviação, por exemplo, o ato de pousar a aeronave obedece a preceitos rigorosamente prescritos, o que não impede os pilotos (notadamente os mais experientes) a buscarem suas "assinaturas", suas formas peculiares de pousar com segurança suficiente para não eludir o prescrito, mas de forma suficientemente estilizada para escapar à mesmice de um pouso como tantos outros (JOUANNEAUX, 1999).

O aporte teórico da psicologia geral histórico-cultural fica aqui esboçado em termos de uma proposta cogenética e dialógica de abordagem do self humano (ROMMETVEIT, 2003; LYRA; BERTAU, 2008; MARKOVÀ, 2000; 2006). Tal abordagem é necessariamente desenvolvimental: Vigotski observa, figurativamente, que é "[...] somente em movimento que um corpo mostra suas propriedades" (VYGOTSKI, 1978, 1985, 2014). A ênfase no dinamismo dos processos em análise é, portanto, central na psicologia histórico-cultural. Para Zanella et al. (2007), o entendimento desse dinamismo, desse movimento é "fundamento" da psicologia históricocultural: "Movimento entre o começo e o fim do desenvolvimento, entre a plasticidade e a petrificação, entre o que foi, o que é e o que pode vir a ser" (ZANELLA et al., 2007, p.31). Para Scheller (2013), a devida compreensão da ênfase dialógico-desenvolvimental para uma psicologia que se pretende geral implica levar em conta dois aspectos: em primeiro lugar, somente é possível compreender as especificações e diferenciações de processos intra ou interindividuais, em contexto histórico-cultural mais amplo, se atentarmos para as colisões que ocorrerão entre elas (POLITZER, 1969; 2003; BENNEFOND; SCHELLER, 2013); em segundo lugar, as diferenças causadoras de colisões serão fonte de desenvolvimento na medida em que ensejarem vivências (perezhivanie - conforme Veresov (2014)) dramáticas, nas quais as experiências subjetivas se co-constróem ao longo do tempo e em função da experiência biográfica. Vale ressaltar que esse último preceito permite entender a ampliação da abordagem desenvolvimental para todo tempo de vida do indivíduo, sem restringir a ideia de desenvolvimento a períodos da infância e adolescência.

Estabelecidos, mesmo que de forma breve, os marcos referenciais da psicologia históricocultural que avança em termos de proposta de saída para a crise histórica da psicologia (VYGOTSKI, 2010), é possível também observar o quanto esta psicologia do trabalho tributária de uma psicologia histórico-cultural pode, em sentido inverso, subsidiar a psicologia geral. Este é o foco da seção seguinte do presente artigo. 


\section{Da psicologia do trabalho à psicologia geral}

É a instrumentação simbólica e técnica de um coletivo de trabalho que vivencia a experiência das solidariedades reais ou fragmentadas de sua história passada e futura.

[...] Poder-se-ia pensar que esta instrumentação simbólica funciona, de certa maneira, como uma lupa para a psicologia em geral. Yves Clot, La fonction psychologique du travail, Cap.5, p. $164^{19}$

A organização sistêmica do edifício teórico proposto pela psicologia histórico-cultural é ilustrativamente resumida por Da Rocha Falcão (2019a; 2019b) com base na metáfora das matrioskas: a figura 1 ilustra os itens obrigatórios para a construção teórica em qualquer domínio teórico, enquanto que as figuras 2 e 3 ilustram, respectivamente, a devida adaptação desses pressupostos conceituais para a construção de uma psicologia geral capaz de propor alternativa real para a crise histórica dessa ciência (VYGOTSKY, 2010), e a construção de uma psicologia do trabalho quem tem essa psicologia geral como quadro de referência:

Figura 1: Níveis de análise obrigatórios para a construção de teoria em qualquer domínio teórico

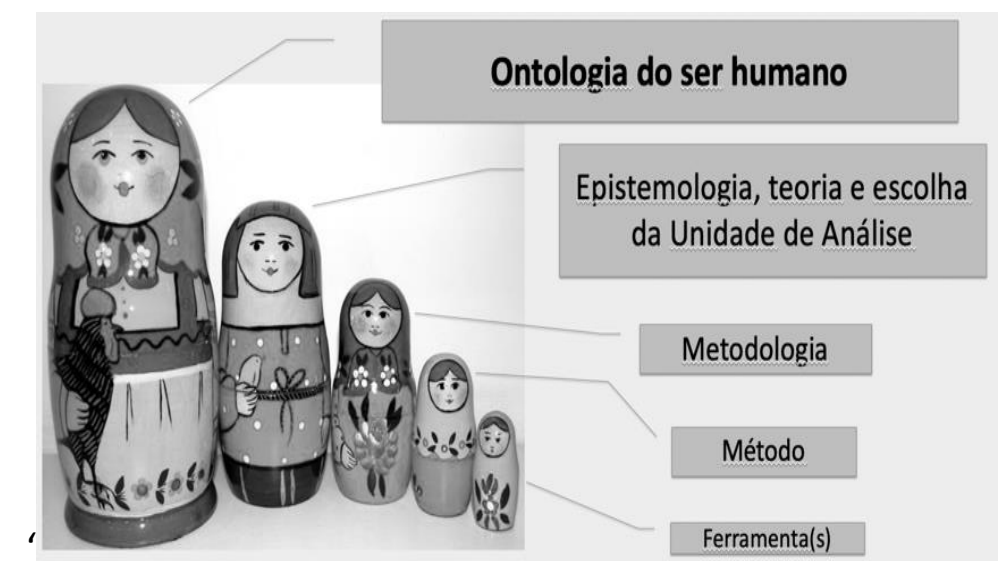

Fonte: (reproduzido de Da Rocha Falcão, 2019a; Da Rocha Falcão, 2020b).

19 “C'est l'instrumentation symbolique et technique d'un collectif de travail qui éprouve, à travers elle, les solidarités réeles ou déchirées de son histoire passé et à venir. [...] Du coup on peut penser qu'elle fonctionne un peu comme une loupe pour la psychologie en générale".

Periódico Horizontes - USF - Itatiba, SP - Brasil - e021029 
Figura 2: Níveis de análise para a construção de uma psicologia geral

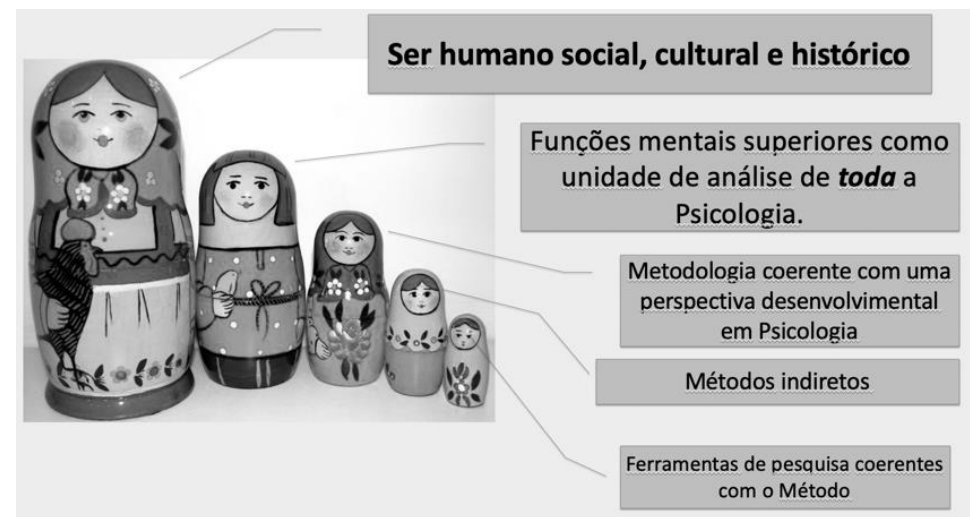

Fonte: (reproduzido de Da Rocha Falcão, 2019a; Da Rocha Falcão, 2020b).

Figura 3: Níveis de análise para a construção de uma psicologia do trabalho fundada em psicologia histórico-cultural

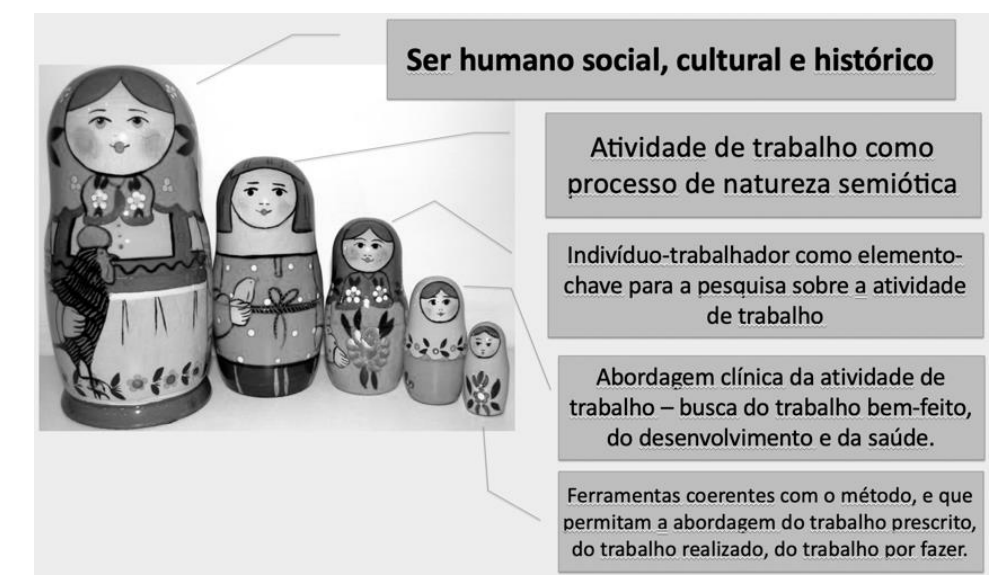

Fonte: (reproduzido de Da Rocha Falcão, 2019a; Da Rocha Falcão, 2020b).

A psicologia do trabalho fornece à psicologia geral elementos empíricos específicos que "corporificam" premissas gerais dessa última, como a cogênese das funções mentais superiores. Ao aludir à atividade de trabalho realizada por cada trabalhador, e que necessariamente tem lugar nos gêneros e é modulada por esses gêneros, constituindo-se em "correias de transmissão entre a vida real e os signos da linguagem" (BAKHTIN, 1988; BAKHTINE/VOLOCHINOV, 1977 apud CLOT, 1999, p.165). A atividade de trabalho, segunda proposta dessa psicologia do trabalho, estabelecerá a diferença, a partir da contribuição de Leontiev (LEONTIEV, 1977, 1984), entre ação, operação e atividade (CLOT, 1999, p.169). Tal diferenciação surge para aprofundar a abordagem da atividade de trabalho como unidade de análise de uma psicologia do trabalho sistematizadas pela Clínica da Atividade (CLOT, 1999, 2008; CLOT; FAÏTA, 2000), mas oferece retrospectivamente contribuição de relevo para a psicologia em geral. Na análise que se tornou 
emblemática da atividade de trabalho dos condutores de trem em Paris e subúrbios, Clot chama a atenção para a necessidade de se considerarem ações do condutor, como por exemplo as frenagens e mesmo imobilizações do trem fora das estações, que parecem se contrapor ao objeto imediato do trabalho deste condutor, que é fazer seu trem chegar à estação-terminal em tempo hábil. Ocorre, contudo, que as situações de congestionamento de trens em horários de pico, para as quais preceitos de segurança se constituem em balizadores importantes da atividade de trabalho, configuram contexto em que as frenagens se coadunam com o objetivo maior dos condutores dos trens - chegar à estação terminal em segurança. Tais ações, como as frenagens, abarcam operações específicas, que demandam automatismos de "gestos de ofício"20" que somente uma história de prática diária na cabine de comando dos trens pode de fato ensejar. A produção bakhtiniana em filosofia e teoria da linguagem se faz presente na psicologia do trabalho proposta pela Clínica da Atividade (CLOT, 1997) também através dos conceitos de estilização e catacrese (BAKHTIN, 1988; BAKHTINE/VOLOCHINOV, 1977; BAKHTINE, 1984; CLOT, 1997).

Para a perspectiva proposta pela Clínica da Atividade, o trabalho atua como mediador do desenvolvimento, saúde e adoecimento. Nesse sentido, trata necessariamente dos coletivos e do gênero profissional, e da interlocução cogenética indivíduop-gênero, via coletivo. Para Clot e Faïta (2000), o gênero de atividades profissionais é funcional na medida em que fornece, ao mesmo tempo, dificuldades e recursos ${ }^{21}$ aos profissionais para controlar seus atos na direção das relações aos objetos e relação entre as pessoas ${ }^{22}$ no contexto de trabalho. Estes mesmos autores, aludindo à matriz teórica bakhtiniana de onde foram importados os operadores teóricos "gênero" e "estilização", observam que, como ocorre nos gêneros de discursos, "[...] o gênero profissional pode ser apresentado como uma espécie de pré-fabricados, um estoque de maneiras diversificadas de 'por em atos' e 'por em palavras' [aspectos relacionados ao contexto de atividade de trabalho], mas também [de prover] conceptualizações pragmáticas ${ }^{23 \prime \prime}$ (p.11).

\footnotetext{
${ }^{20}$ Aludimos aqui aos "gestes de métier", as habilidades gestuais que contribuem para configurar rotinas em muitas atividades profissionais (SENNETT, 2010).

21 "[...] des contraintes et des ressources" (CLOT; FAÏTA, 2000, p.13).

22 “[...] les rapports aux objets et entre les personnes [...]" (CLOT; FAÏTA, 2000, p.10).

23 “Le genre professionnel peut être présenté comme une sorte de préfabriqué, stock de 'mises en actes', de 'mises en mots', mais aussi de conceptualisations pragmatiques [...]” (CLOT; FAïTA, 2000, p13). Negritos acrescentados.
} 
Os trabalhadores dispõem portanto de referenciamento proporcionado por determinado gênero profissional para poder agir em contexto de trabalho, pois, conforme aludido por $\mathrm{M}$. Bakhtine, referindo-se aos contextos discursivos de forma geral, "se tivéssemos sempre de criar pela primeira vez, nas interlocuções, cada um dos nossos enunciados, essas interlocuções seriam impossíveis"24. (Bakhtine, 1984, p.285).

Em última análise, o gênero profissional diz respeito à

[...] parte subentendida da atividade daquilo que os trabalhadores de um determinado meio conhecem e veem, esperam e reconhecem, apreciam e temem; aquilo que lhes é comum, e que os reúne sob condições reais de vida; aquilo que eles sabem dever fazer graças a uma comunidade de avaliações pressupostas, sem que seja necessário reespecificar a tarefa a cada vez que ela se apresenta ${ }^{25}$ (CLOT; FAїTA, 2000, p.11).

Cabe aos trabalhadores, no contexto do trabalho realizado, alterarem (ou "estilizarem") as especificações originárias do gênero profissional, na medida em que o trabalho prescrito jamais poderá se realizar no trabalho efetivamente feito. Aquele que trabalha, portanto, sempre o faz a partir de determinado gênero, ao qual este trabalhador se submete ao mesmo tempo em que o subverte ou inova com seu estilo pessoal, em função de seu poder de agir (CLOT, 2008). Compreender esse ponto permite compreender a conclusão de Clot e Faïta (2000, p.13), segundo a qual o gênero está sempre e necessariamente inacabado. Os confrontos entre variantes estilísticas e gêneros de referenciamento caracterizam a vitalidade dos gêneros em termos de promover saúde e desenvolvimento no contexto da atividade de trabalho, ao passo que o estiolamento (ou inexistência) do gênero acarretarão a precarização da atividade profissional (DA ROCHA FALCÃO, SILVA MESSIAS; MASCARENHAS DE ANDRADE, 2020a, 2020b).

A dinâmica de referenciamento do trabalhador por seu gênero profissional encontra no conceito bakhtiniano de catacrese ilustração, no trabalho, de dinâmica que ultrapassa esse contexto e retroalimenta uma psicologia geral histórico-cultural. No domínio das ciências da

\footnotetext{
${ }^{24} S^{\prime}$ il nous fallait créer pour la première fois dans l'échange chacun de nos énoncés, cet échange serait impossible.

25 "Le genre est en quelque sorte la partie sous-entendue de l'activité, ce que les travailleurs d'un milieu donné connaissent et voient, attendent et reconnaissent, apprécient ou redoutent ; ce qui leur est commun et qui les réunit sous des conditions réelles de vie ; ce qu'ils savent devoir faire grâce à une communauté d'évaluations présupposées, sans qu'il soit nécessaire de respécifier la tâche chaque fois qu'elle se présente". (CLOT; FAïTA, 2000, p.11).
}

Periódico Horizontes - USF - Itatiba, SP - Brasil - e021029 
linguagem, a catacrese caracteriza figuras de linguagem como "braços" de uma poltrona, "alças" de uma rodovia, situações em que aludimos a um termo figurativamente, na falta de termo mais específico (CLOT, 1997). No âmbito do trabalho, as catacreses ocorrerão sempre que se fizer uso imprevisto/não programado de ferramentas, rotinas para tarefas, gestos de "métier". Clot (1999, cap.2, La fonction psychologique du travail) ilustra esse ponto ao referir-se ao caso de trabalhadora que se serve de chave-de-fenda (ao invés da chave convencional) para abrir quadro de controle de máquinas (primeira contravenção), o que ultrapassa o rol de atividades previstas em sua função profissional específica (mas ao mesmo tempo evita sua interrupção), função essa que não abarcava esse tipo de iniciativa (manutenção dos equipamentos), reservado a profissional específico (segunda contravenção). Esse profissional, ressalta Clot, tem interesse em fazer "vista grossa" (ou até auxiliar) a colega nessa catacrese funcional, tendo em vista o alívio na carga de suas atribuições, e manutenção de certa "normalidade de superfície" para as atividades em curso na organização de trabalho. O dito popular "se você gosta da atividade de cozinhar, melhor não penetrar na intimidade de uma cozinha real [...]" não se restringe ao. mundo profissional da gastronomia... As catacreses caracterizam toda e qualquer atividade de trabalho, na medida em que em quaisquer dessas atividades ocorrerão situações de inadequação do previsto em relação ao real (seja em termos de equipamentos, seja em termos de rotinas, protocolos, processos). No limite, mesmo no caso em que as prescrições do gênero profissional pareçam atuais, suficientes, abrangentes, explícitas e, no limite, monoglóssicas, o caráter semiótico da linguagem, na base das funções mentais superiores, acarretará, na pior das hipóteses, certa heteroglossia, conducente, na melhor das hipóteses, à poliglossia das construções cogenéticas. Tal princípio teórico, na base da proposição de um self dialógico, encontra nas estilizações e catacreses do contexto de trabalho evidência empírica robusta.

Para finalizar a presente seção deste artigo, propomos indicar aqui três vertentes importantes de contribuição da psicologia do trabalho, em retorno, para a psicologia geral de onde veio:

A descrição da atividade humana comporta necessariamente a distinção entre ações, objetos e operações (LEONTIEV, 1977, 1984; CLOT, 1999). Quem realiza determinada atividade de trabalho, seja a inspeção de um cadáver, seja a condução pedagógica em sala de aula (DA ROCHA FALCÃO, SILVA MESSIAS; MASCARENHAS DE ANDRADE, 2020a, 2020b), tem um 
objeto para seu trabalho (identificar causa mortis ou proporcionar aprendizagem conforme metas programáticas), para o qual realiza ações (como trepanar crânios ou projetar slides de aula), agrupáveis em operações (como o circuito de recepção e devolução de cadáver ou abordagem de um tópico programático como representações algébricas), tudo isso no contexto do rol complexo de iniciativas, atitudes, emoções e afetos que atravessam a atividade profissional como tal, a própria identificação como "tanatoscopista" ou "docente do ensino fundamental", ou melhor ainda: a vivência de fazer, no dia-a-dia, um trabalho bem feito ("métier bien fait" - conforme Clot, (2008)), vivência que somente se sustenta com o respaldo do coletivo de trabalho, instância que corporifica o gênero profissional. Esse princípio, enraizado no contexto do trabalho, serve para a abordagem das funções mentais superiores em geral ( VYGOTSKI, 2014).

O isolamento, a "solidão" do trabalhador em face de um gênero profissional em regime de esvaziamento (como no caso de atividades profissionais em extinção - conforme Lhuilier (2002); Clot e Lhuilier (2010)), ou gênero profissional rarefeito ou inexistente (BENDASSOLLI; DA ROCHA FALCÃO, 2013), constituem a matriz de fato relevante para a compreensão (e mesmo abordagem clínica) da precarização do trabalho. Tal dado, para além de aprofundar a compreensão dos processos de precarização da atividade de trabalho, traz elementos importantes para a própria avaliação dos conceitos de saúde e adoecimento psicológico. A abordagem das funções mentais superiores em contexto social, histórico-cultural encontra na noção de poder de agir em atividade de trabalho dados teóricos-empíricos na linha da saúde mental relacionada ao poder de gerar normas de funcionamento em face da diversidade - tratar-se-ia aqui da passagem da "normalidade" para a "normatividade" (CANGUILHEM, 1984). Por essa perspectiva, ter saúde mental não equivale a se aproximar de um estado "normal" (no sentido de assimilável a uma "norma" estatisticamente definida como mais frequente), mas de uma condição capaz de gerar novas normas.

Cabe, finalmente, mencionar aspecto de natureza teórico-metodológica, com rebatimentos epistemológicos. A abordagem da atividade de trabalho oferecida pela Clínica da Atividade, apresentada aqui como representante de uma psicologia do trabalho de orientação histórico-cultural, chama a atenção para o fato de que caberá sempre aos trabalhadores participantes proceder à descrição da atividade de trabalho - seja através de técnicas de 
pesquisa como instrução ao sósia ou autoconfrontação simples e cruzada, seja através de quaisquer outras técnicas que respeitem a centralidade da consideração do papel crucial do trabalhador para descrever sua própria atividade de trabalho (CLOT et al., 2000). A abordagem da atividade de trabalho através de técnicas que conferem ao(s) trabalhador(es) participante o papel central na abordagem e descrição dessas atividades, do que resultam vivências para esse trabalhador que podem eventualmente contribuir para a ampliação terapêutica de seu poder de agir, dão a essa abordagem caráter clínico que opera mudança no status dos trabalhadoresparticipantes, não mais "sujeitos" (no sentido de assujeitados) de procedimentos tradicionais de coleta de dados. Do ponto de vista epistemológico, tem-se aqui pespectiva que ultrapassa uma abordagem do conhecimento como um "objeto" passível de circunscrição objetiva (numa relação "eu-isso", conforme os termos propostos por Martin Buber (1974), para a abordagem do conhecimento como vivência (perezhivanie), aspecto constituinte de um fluir biográfico que é simultaneamente descrito e (re)vivido.

\section{Conclusões}

O presente artigo buscou, em última análise, propor espaço de reflexão metateórico. Fontes e Da Rocha Falcão (2015) observam o quanto tal reflexão, juntamente com o esforço de apuro conceitual, tem sido necessária (porém desconsiderada) em Psicologia. Temos nos guiado, por tradição histórica empiricista, pelo mantra do "show me your data"6". Tal postura, além de condenar muitas vertentes da psicologia à circunscrição da psicotécnica, ajuda a explicar a célebre (e dolorosa para nossa autoestima de trabalhadores intelectuais em psicologia) avaliação de Wittgenstein, para quem "há na Psicologia métodos experimentais e confusão conceitual" (WITTGENSTEIN, 1996, p.206 apud FONTES; DA ROCHA FALCÃO, 2015, p.72). Para Aaro Toomela, a ênfase reificadora de dados empíricos e abordagens quantitativas tem gerado, na psicologia, uma quantidade imensa de esforço intelectual que se tornou "inevitável e inútil" (TOOMELA, 2010).

\footnotetext{
26 "Mostre-me seus dados [...] e me poupe de elucubração teórica [...] em conformidade com a perspectiva segundo a qual os dados oriundos da experiência empírica seriam a fonte última dos conceitos e do conhecimento - [...] sense experience is the ultimate source of all our concepts and knowledge." Disponivel em: https://plato.stanford.edu/entries/rationalism-empiricism/.
} 
Retomando o ponto a que aludimos já na seção de introdução do presente artigo, os textos mais populares de história da psicologia referem que este domínio do conhecimento nasce, "como ciência", a partir da criação do primeiro laboratório de psicologia no Instituto Experimental de Psicologia da Universidade de Leipzig-Alemanha, em 1879; concomitantemente, são publicados, por este mesmo autor, os Principles of Physiological Psychology, em que se busca “[...] demarcar um novo domínio da ciência” ${ }^{27}$ (). Lev Vygotski, em livro absolutamente crucial no qual se propõe a analisar a crise constitutiva da psicologia desde seu nascedouro, refere-se a essa iniciativa histórica de Wundt como o marco de criação, senão da psicologia "como ciência", de ponto de partida de um dissenso entre defensores de uma "psicologia espiritualista do ato consciente e do pensamento" (Idealistas), e defensores de uma psicologia "natural-científica", passível de ser descrita com os mesmos conceitos da física."(VYGOTSKI, 2010, p.249). Para Vygotski, estariam dados, nesse momento histórico (anos 20 do século passado), as bases de crise duradoura na psicologia - presente até a contemporaneidade. Neste mesmo livro em que analisa o contexto histórico-científico da emergência da crise em psicologia, o referido autor destaca os esforços então em voga para superá-la. O debate sobre tais esforços permanecem até hoje, e foram um dos pontos motivadores da reflexão aqui proposta.

As considerações feitas até aqui nos conduzem, finalmente, à importância, e mesmo necessidade epistemológica de se dispor de uma psicologia geral digna desse nome, e à defesa da tese segundo a qual essa psicologia seria a proposta histórico-cultural se não finalizada, iniciada por Lev Vigotski. Essa psicologia geral, conforme se discutiu, enquadra psicologias derivadas, como no caso específico de interesse aqui, uma psicologia do trabalho. Se considerarmos, como Clot, que a atividade de trabalho seria "a mais humana das atividades" (CLOT, 1999), estariam esboçadas, nessa afirmação, as condições para que a psicologia do trabalho, cogeneticamente, contribua para o desenvolvimento da psicologia geral de onde veio (e para onde, portanto, retorna). Tempos de crise e drama (no sentido originariamente proposto por Politzer (2003)) como são os tempos atuais durante os quais se consuma a produção do presente artigo, tempos em que a humanidade inteira é confrontada com pandemia que ameaça

\footnotetext{
${ }^{27}$ Disponível em: https://pt.wikipedia.org/wiki/Wilhelm_Wundt.
} 
a humanidade em termos de domínios centrais - a sobrevivência biológica, emocional e econômica - são tempos que têm demandado às ciências e aos ofícios profissionais um auxílio relevante para a vivência das colisões dramáticas oriundas do adoecimento, da morte, do luto, da perda de lugar no mundo do trabalho, do abalo grave nas condições de trabalho, seja por seu deslocamento dos escritórios para as casas, seja pelos novos desafios do trabalho remoto (FERREIRA; DA ROCHA FALCÃO, 2020). Hoje, mais do que nunca, a psicologia do trabalho precisa ser eficaz para ser relevante, e para ser eficaz, precisa ultrapassar a condição de psicotécnica, dos cuidados pontuais genéricos (mesmo que pontualmente eficazes), para atingir a abrangência de um domínio da ciência psicológica inteira. Hoje, o desafio que a crise acima aludida engendra força a psicologia, no contexto das iniciativas humanas, a explicitar teorias, metodologia, métodos, ferramentas e protocolos, sem os quais ela seria, no máximo, um "educated guess" destinado a uso e descarte instantâneos. A psicologia do trabalho que se inspira na psicologia histórico-cultural não garante resultados, mas provê os meios para que se afronte produtivamente e rigorosamente tal desafio da contemporaneidade.

\section{Referências}

BAKHTIN, M. Filosofia da linguagem e seu funcionamento. Porto Alegre: Artes Médicas, 1988.

BAKHTINE, M.; VOLOCHINOV, V.N. Le marxisme et la philosophie du langage: essai d'application de la méthode sociologique en linguistique. Paris: Les Éditions du Minuit, 1977.

BAKHTINE, M. Parte III: les genres de discours. In: BAKHTINE, M. Esthétique de la création verbale. Paris: Gallimard, 1984, p.263-308.

BENDASSOLLI, P. F.; DA ROCHA FALCÃO, J. T. Psicologia social do trabalho sujo: revendo conceitos e pensando em possibilidades teóricas para a agenda da psicologia nos contextos de trabalho. Universitas Psychologica, v.12, p.1155-1168, 2013.

BONNEFOND, J.-Y., SCHELLER, L. Vygotski lecteur de Politzer: pour une psychologie concrète du développement des fonctions psychiques supérieures - un cas de transformation fonctionnelle dans une entreprise industrielle - histoire, culture, développement: questions théoriques, recherches empiriques. In: SEMINAIRE INTERNATIONAL VYGOTSKI, 6., 2015, Paris. Anais [...], CNAM, Paris, 2015.

BUBER, M. Eu e tu. São Paulo: Moraes, 1974. 
BRUNER, J. Celebrating divergence: Piaget and Vygotsky. Human Development, v.40, n.2, p.6373, 1997. Disponível em: https://doi.org/10.1159/000278705. Acesso em: 28 maio 2021.

CANGUILHEM, G. Le normal et le pathologique. Paris: Presses Universitaires de France, 1984.

CLOT, Y. Le problèmes des catachrèses en psychologie du travail: un cadre d'analyse. Le Travail Humain. v. 60, n.2, p.113-129, 1997.

CLOT, Y. La fonction psychologique du travail. Paris, Presses Universitaires de France, 1999.

CLOT, Y. Vygotski: para além da psicologia Cognitiva. Pro-Posições, v.17, n.2, p.19-30, maio/ago. 2006.

CLOT, Y. Travail et pouvoir d'agir. Paris, Le Travail Humain - Presses Universitaires de France, 2008.

CLOT, Y. A psicologia do trabalho na França e a perspectiva da clínica da atividade. Fractal: Revista de Psicologia, v.22, n. 1, p.207-234, 2010a. Disponível em:

https://tinyurl.com/9mn9a8au. Acesso em: 28 maio 2021.

CLOT, Y. Seminário para pós-graduandos no CNAM (Conservatoire National des Arts et Métiers), não-publicado. Paris, 2010b.

CLOT, Y. Vygotski maintenant. Paris, La Dispute, 2012.

CLOT, Y.; FAÏTA, D. Genres et styles en analyse du travail: concepts et méthodes. Travailler, n.4, p.7-42, 2000.

CLOT, Y.; FAÏTA, D.; FERNANDEZ, G.; SCHELLER, L. Entretiens en autoconfrontation croisée : une méthode en clinique de l'activité. Pistes - Réflexions sur la pratique. v.2, n.1, p.1-7, 2000.

CLOT, Y., LHUILIER, D. Travail et santé. Paris, Érès, 2010.

DA ROCHA FALCÃO, J. T. Na vida dez, na escola dez: breve discussão crítica acerca de pressuspostos psicológicos e seus desdobramentos sobre a avaliação em matemática escolar. Vértices, v.10, p.117-139, 2009.

DA ROCHA FALCÃO, J. T. ... em busca "(...) de uma matriz teórica que possa nos servir de referência para nossas pesquisas (...)" em Psicologia do Trabalho. In: CONGRESSO INTERNACIONAL DA CLÍNICA DA ATIVIDADE - CICA, 4., 2019, Braganca Paulista. 2019a.

DA ROCHA FALCÃO, J. T. As colisões dramáticas como operadores teóricos cruciais para a abordagem histórico-cultural da atividade de trabalho. In: CONGRESSO INTERNACIONAL DA CLÍNICA DA ATIVIDADE - CICA, 4., Braganca Paulista, 2019b. 
DA ROCHA FALCÃO, J. T., SILVA MESSIAS, J., MASCARENHAS DE ANDRADE, L. R. O trabalho precário e o trabalho precarizado. In: FERREIRA, M. C., DA ROCHA FALCÃO, J. T. (orgs.). Intensificação, precarização, esvaziamento do trabalho e margens de enfrentamento. p.74-99. Natal, Editora da UFRN, 2020a.

DA ROCHA FALCÃO, J. T., SILVA MESSIAS, J., MASCARENHAS DE ANDRADE, L. R. Trabalho formal, informal, precário e precarizado: nuances da atividade laboral contemporânea na gênese da saúde e do adoecimento. In: OSÓRIO, C. (org.). O trabalho como operador de saúde. 2020b. [Livro em preparação].

FERREIRA, M. C., DA ROCHA FALCÃO, J. T. Trabalho em contexto de pandemia, saúde mental e qualidade de vida no trabalho: diretrizes essenciais. In: Os impactos da pandemia da COVID-19 no trabalho, 3: pandemia da Covid-19: impactos na saúde e na qualidade de vida do trabalhador. 2020. [Livro em preparação].

FONTES, F. F.; DA ROCHA FALCÃO, J. T. A psicologia teórica e filosófica como uma área de pesquisa acadêmica. Psicologia em Pesquisa, UFJF, v.9, n.1, p.72-79, 2015. DOI: 10.5327/Z19821247201500010009. Dispinível em: https://tinyurl.com/bne6r3sp. Acesso em: 27 maio 2021.

JOUANNEAUX, M. Le pilote est toujours devant. Toulouse, Octarès, 1999.

KOPPE, S. A moderate eclecticism: ontological and epistemological issues. Integrative Psychological and Behavioral Science, v.46, p.1-19, 2011.

KUHN, T. S. A estrutura das revoluções científicas. São Paulo: Editora Perspectiva, 1978.

LAKATOS, I. La metodologia de los programas de pesquisa. Madrid: Alianza, 1987.

LEONTIEV, A. O desenvolvimento do psiquismo. São Paulo: Moraes, 1977.

LEONTIEV, A. Activité, conscience, personnalité. Paris-Moscou, Éditions du Progrès, 1984.

LHUILIER, D. Placardisés. Des exclus dans l'entreprise. Paris: Seuil, 2002.

LHUILIER, D. Le sale boulot. Travailler, v.2, n.14, 73-98, 2005.

LYRA, M. C. D. P, BERTAU, M. C. Dialogical practices as basis for self. Studia Psychologica, UKSW, n.8, p.173-193, 2008.

MARKOVÀ, I. Amèdèe or how to get rid of it: social representations from a dialogical perspective. Culture \& Psychology, v.6, n.4, p.419-460, 2000.

MARKOVÀ, I. Dialogicidade e representações sociais: as dinâmicas da mente. Petrópolis, Editora Vozes, 2006. 
PASTRÉ, P.; MAYEN, P.; VERGNAUD, G. La didactique professionnelle, Revue Française de Pédagogie [En ligne], n.154, p.145-198, jan.-mar. 2006. Disponível em:

http://rfp.revues.org/157. Acesso em: 27 maio 2021.

POLITZER, G., Psychologie mythologique et psychologie scientifique: où va la psychologie concrète ?. In: POLITZER, G. Écrits 2. Les fondements de la psychologie. Paris: Éd. Sociales, 1969, 57-188.

POLITZER, G., Critique des fondements de la psychologie. Paris: PUF, 2003.

ROMMETVEIT, R. On the role of "a psychology of the second person" in studies of meaning, language, and mind. Mind, culture and activity. v.10, n.3, p.205-218, 2003.

SCHELLER, L. Un cas: I'augmentation du pouvoir d'agir des facteurs d'un bureau de Poste français. In: COLOQUIO INTERNACIONAL DA CLINICA DA ATIVIDADE: mesa-redonda metodologia e métodos, 2., 2013, Natal. Anais [...]. Natal, 2013.

SENNETT, R. Ce que sait la main: la culture de l'artisanat. Paris, Albin Michel, 2010.

TOASSA, G. Not all that glitters is Marx: analysis of stalinist critiques of Vigotski within the soviet science. Psicologia USP, v.27, n.3, p.553-563. 2016. Disponível em: https://tinyurl.com/yjwa3fsa. Acesso em: 27 maio 2021.

TOOMELA, A. Quantitative methods in psychology: inevitable and useless. Frontiers in Psychology. v.1, p.01-14, 2010. DOI: 10.3389/fpsyg.2010.00029. Acesso em: 27 maio 2021.

VERESOV, N. Marxist and non-marxist aspects of the cultural-historical psychology of L. S. Vygotsky. Outlines, n.1, 2005, p.31-49.

VERESOV, N. Émotions, perezhivanie et développement culturel: le projet inachevé de Lev Vygotski. In: MORO, C., MULLER MIRZA, N. (orgs.). Sémiotique, culture et développement psychologique. Villeneuve d'Ascq: Presses Universitaires du Septentrion, 2014.

VIGOTSKI, L.S. Psicologia, educação e desenvolvimento. Escritos de L.S. Vigotski. São Paulo, Expressão Popular, 2021.

VYGOTSKI, L. S. Histoire du développement des fonctions psychiques supérieures. Paris: La Dispute, 2014.

VYGOTSKI, L. S. La signification historique de la crise en psychologie, Chapître 13, Les tâches d'une psychologie matérialiste. Paris, La Dispute, 2010.

VYGOTSKY, L.S. The problem of the environment. In: VAN DER VEER, R.,VALSINER, J. The Vygotski Reader. Cambridge: Blackwel, 1994, p.338-354. 
VYGOTSKY, L. S. The collected works / Sobranie sochinenii. Moscow, Vol. 1, 1982.

VYGOTSKY, L. S. Pensée et langage. Paris, Editions Sociales. 1985.

ZANELLA, A. V., CASANOVA DOS REIS, A., PIANA TITON, A., URNAU, L. C., RODRIGUES DASSOLER, T. Questões de método em textos de Vygotski: contribuições à pesquisa em psicologia. Psicologia \& Sociedade, v.19, n.2, p.25-33, 2007. Disponível em: https://doi.org/10.1590/S0102-71822007000200004. Acesso em: 27/05/2021.

ZARIFIAN, P. O modelo da competência: trajetória histórica, desafios atuais e propostas. São Paulo, Senac Editora, 2003.

ZARIFIAN, P. Le travail et la compétence: entre puissance et contrôle. Paris, Presses Universitaires de France, 2009.

\section{AGRADECIMENTOS}

O autor registra aqui a dívida intelectual do presente artigo em relação a pontos de reflexão desenvolvidos pelos colegas Oswaldo Yamamoto e Isabel Fernandes (UFRN).

Recebido em outubro 2020.

Aprovado em abril 2021. 